\title{
Telomere length is maternally inherited and associated with lipid metabolism in Chinese population
}

\author{
Liyun Guo ${ }^{1,3,{ }^{*}}$, Yajuan Chen ${ }^{2,}{ }^{*}$, Huiqin $\mathrm{Li}^{1}$, Fanqian Yin ${ }^{1,4}$, Mingxia Ge ${ }^{1,4}$, Li Hu${ }^{1,5}$, Meiting Zi ${ }^{1}$, \\ Zhenghong Qin ${ }^{3}$, Yonghan $\mathrm{He}^{1}$
}

${ }^{1}$ Key Laboratory of Healthy Aging Research of Yunnan Province, Kunming Institute of Zoology, Chinese Academy of Sciences, Kunming 650201, China

${ }^{2}$ School of Rehabilitation, Kunming Medical University, Kunming 650500, China

${ }^{3}$ Department of Pharmacology and Laboratory of Aging and Nervous Diseases and Jiangsu Key Laboratory of Neuropsychiatric Diseases, College of Pharmaceutical Sciences, Soochow University, Suzhou 215123, China

${ }^{4}$ Kunming College of Life Science, University of Chinese Academy of Sciences, Beijing 100049, China

${ }^{5}$ College of Basic Medicine and Life Sciences, Hainan Medical University, Haikou 571199, China

*Equal contribution

Correspondence to: Yonghan He; email: heyonghan@mail.kiz.ac.cn

Keywords: telomere length, heredity, visceral fat, lipid metabolism

Received: June 24, $2021 \quad$ Accepted: December 25, 2021

Published: January 7, 2022

Copyright: (C) 2022 Guo et al. This is an open access article distributed under the terms of the Creative Commons Attribution License (CC BY 3.0), which permits unrestricted use, distribution, and reproduction in any medium, provided the original author and source are credited.

\section{ABSTRACT}

Telomere is a unique DNA-protein complex which covers the ends of chromosomes to avoid end fusion and maintain the stability and integrity of chromosomes. Telomere length (TL) shortening has been linked to aging and various age-related diseases in humans. Here we recruited a total of 1031 Chinese individuals aged between 12 and 111 years, including 108 families with parents and their offspring. DNA was extracted from peripheral white blood cells and TL was measured by quantitative PCR (qPCR). We explored the associations of TL with age, gender and clinical variables, and tested the parental effects on TL variation. First, we found that TL was shortened with age, however, TL was better maintained in females than males. Second, there was a robust association of TL between mother and offspring, but not between father and their offspring. In addition, TL was inversely associated with visceral fat index in females, and positively associated with apolipoprotein A levels. Knockdown of the key genes for lipid metabolism (PNPLA2 and CPT1) shortened the TL in HepG2 cells. These findings indicate that TL is maternally inherited, and impairment of lipid metabolism may contribute to the TL shortening in the Chinese population.

\section{INTRODUCTION}

Telomere is a unique DNA-protein complex consisting of repetitive DNA sequences (TTAGGG ${ }_{n}$ ) and several associated protective proteins at the end of linear chromosomes [1,2], which caps the chromosomal end and protects it from end-to-end fusing [3], consequently maintains DNA stability [4]. The telomere plays critical roles in meiotic chromosome segregation and chromosome silencing. Telomere length (TL) has been shown to associate with replicative potential. It was inversely associated with cell passage in cell culture, and with age at the organism level in vivo [3, 5, 6]. TL in blood cells has been studied extensively as a biomarker of human aging because its shortening is associated with lifespan $[6,7]$, and various age-related diseases $[6,8,9]$. Therefore, identifying determinants for TL has become a focus in telomere biology.

Factors influencing TL are not fully known, however it is likely that both genetic and various environmental 
factors, or their interactions play roles. For example, monozygotic and dizygotic twins studies indicate that mean TL and chromosome-specific TL patterns were in part inherited [10], with an estimated heritability ranging from $36 \%$ to $90 \%$ [11]. An earlier study reported that the inheritance of TL was associated with the $\mathrm{X}$ chromosome [12], but another two reports supported paternal inheritance of telomere [13, 14]. In contrast, there was a study reporting no significant differences in the father-offspring or mother-offspring TL correlation degree [15]. Thus far, the inheritance pattern of TL seems controversial and has been questioned.

Several other factors, such as obesity [16-18], pulse pressure [19], physical activity [20, 21], life stressors [22], and smoking [23], have been shown to impact TL, possibly through oxidative stress or inflammation [24, 25]. Likewise, the associations of these factors with TL are inconsistent across different studies. Most of the above studies were performed in Caucasians, and few of them were in East Asian population. Given the critical role of telomere in aging and age-related diseases, data from Asian populations are needed to identify and confirm the factors that may affect TL.

Here we explored the inheritance pattern of TL in 1031 Chinese individuals containing 108 families with parents and their offspring, and found a robust TL association between mothers and their offspring, supporting that TL is maternally inherited. Among the clinical variables, we showed that TL was inversely associated with visceral fat mass, but positively associated with apolipoprotein A (ApoA) levels, suggesting the TL is likely to be affected by lipid metabolism. Interference of the genes involved in lipid metabolism caused lipid accumulation and shortened $\mathrm{TL}$ in vitro. These findings suggest that TL is maternally inherited and is partially affected by lipid metabolism in Chinese.

\section{RESULTS}

\section{General characteristics of the participants}

Table 1 shows the basic characteristics of the studied population grouped by age at recruitment from -49 to $100+$. Among them, 720 were females and 289 were males. Gender information in 5 subjects was unavailable. As shown in Table 1, most of the parameters were age-related $(\mathrm{p}<0.0001)$. Most of the indicators gradually increased or decreased along with age (Table 1), while some increased initially and then decreased with age, which is associated with the inclusion of the long-lived subjects (aged 90+) who usually have a specific metabolic profile as described in our and other studies [26-29]. Specifically, the levels of systolic blood pressure (SBP), alanine transaminase (AST) and creatinine (Cre) increased along with age; the opposite trend appeared in height, weight, bone mass (BOM), basic metabolism rate (BMR) and body fat rate (BFR). Surprisingly, the diastolic blood pressure (DBP), total cholesterol (TC), triglyceride (TG) and lowdensity lipoprotein (LDL) were improved at extreme age, which increased with age before $80 \mathrm{yr}$ but decreased after 90 yr. In addition, high-density lipoprotein (HDL) and total bilirubin (TB) were not significantly changed among different age groups (Table 1).

\section{The telomere length is better maintained in females than males}

Since the TL is a marker of aging, we first analyzed the changes of TL with age from 49 to $100+$ yr. As shown in Figure 1, TL was negatively correlated with age in both male and female subjects as expected (female: $r=0.34, p<0.0001$, Figure 1A; male: $r=0.46$, $\mathrm{p}<0.0001$, Figure 1B), but the correlation between TL and age was significantly higher in males than in females $(p=0.038)$. There were not any differences in TL between neighboring age groups before 90 years in females (Figure 1C). In males, TL was significantly shortened in 60-69 and 90-99 age groups than 50-59 and 70-79 age groups, respectively (Figure 1D). However, there were not significant gender differences in the mean TL among different age groups (Supplementary Table 1). These observations suggest that telomere attrition may be accelerated in males than females when they are old.

\section{TL is maternally inherited}

TL has been reported to be affected by genetic factors in Caucasian populations [10, 12, 13]. Here we tested the association of TL between parents and their F1 offspring to see whether there is a genetic basis for TL. As shown in Table 2 and Supplementary Figure 1, there was a significant correlation in TL between mother and offspring ( $\mathrm{r}=0.44, \mathrm{p}=0.0001$, Supplementary Figure $1 \mathrm{~A}$ and Table 2). Among them, the motherdaughter TL correlation was higher than mother-son TL correlation (mother-daughter: $\mathrm{r}=0.62, \mathrm{p}=0.01$, Supplementary Figure 1B and Table 2; mother-son: $\mathrm{r}=0.35, \mathrm{p}=0.01$, Supplementary Figure $1 \mathrm{C}$ and Table 2 ). However, we did not observe any correlations between father and their offspring $(\mathrm{r}=0.23, \mathrm{p}=0.36$, Supplementary Figure 1D and Table 2), neither between father-daughter $(\mathrm{r}=0.41, \mathrm{p}=0.36$, Supplementary Figure 1E and Table 2) nor father-son ( $r=0.19$, $\mathrm{p}=0.46$, Supplementary Figure $1 \mathrm{~F}$ and Table 2). These findings suggest that TL is maternally inherited in the Chinese population. 
Table 1. General clinical characteristics of the participants.

\begin{tabular}{|c|c|c|c|c|c|c|c|c|c|c|c|c|c|}
\hline & \multicolumn{13}{|c|}{ Age (y) } \\
\hline & \multicolumn{2}{|r|}{-49} & \multicolumn{2}{|r|}{$50-59$} & \multicolumn{2}{|r|}{$60-69$} & \multicolumn{2}{|c|}{ 70-79 } & \multicolumn{2}{|r|}{ 90-99 } & \multicolumn{2}{|r|}{$100+$} & \multirow[t]{2}{*}{$p$-value } \\
\hline & $\mathrm{N}$ & $\operatorname{Mean}( \pm \mathrm{SD})$ & $\mathrm{N}$ & $\operatorname{Mean}( \pm \mathrm{SD})$ & $\mathrm{N}$ & $\operatorname{Mean}( \pm \mathrm{SD})$ & $\mathrm{N}$ & $\operatorname{Mean}( \pm \mathrm{SD})$ & $\mathrm{N}$ & $\operatorname{Mean}( \pm \mathrm{SD})$ & $\mathrm{N}$ & $\operatorname{Mean}( \pm \mathrm{SD})$ & \\
\hline Height $(\mathrm{cm})$ & 30 & $154.8( \pm 5.9)$ & 53 & $150.6( \pm 27.7)$ & 77 & $153.1( \pm 6.9)$ & 35 & $153.7( \pm 9.2)$ & 187 & $144.1( \pm 14.0)$ & 12 & $143.8( \pm 8.3)$ & 0.000 \\
\hline Weight (kg) & 30 & $57.2( \pm 11.0)$ & 53 & $57.2( \pm 11.2)$ & 75 & $54.1( \pm 9.3)$ & 35 & $53.5( \pm 11.2)$ & 188 & $40.6( \pm 9.6)$ & 12 & $41.0( \pm 9.0)$ & 0.000 \\
\hline Glu (mmol/L) & 46 & $6.17( \pm 1.69)$ & 81 & $6.85( \pm 2.41)$ & 100 & $6.68( \pm 1.72)$ & 46 & $6.92( \pm 1.87)$ & 286 & $7.57( \pm 2.48)$ & 69 & $6.08( \pm 1.29)$ & 0.000 \\
\hline $\mathrm{SBP}(\mathrm{mmHg})$ & 63 & $126( \pm 20)$ & 123 & $37( \pm 21)$ & 147 & $39( \pm 20)$ & 54 & $45( \pm 22)$ & 366 & $144( \pm 25)$ & 109 & $145( \pm 22)$ & 0.000 \\
\hline $\mathrm{DBP}(\mathrm{mmHg})$ & 63 & $83( \pm 13)$ & 123 & $89( \pm 13)$ & 147 & $88( \pm 13)$ & 54 & $91( \pm 15)$ & 366 & $82( \pm 15)$ & 109 & $81( \pm 14)$ & 0.000 \\
\hline $\mathrm{TC}(\mathrm{mmol} / \mathrm{L})$ & 67 & $5.04( \pm 1.47)$ & 125 & $5.47( \pm 1.74)$ & 149 & $5.69( \pm 2.19)$ & 49 & $5.98( \pm 1.23)$ & 417 & $5.05( \pm 1.30)$ & 108 & $4.71( \pm 1.57)$ & 0.000 \\
\hline $\mathrm{TG}(\mathrm{mmol} / \mathrm{L})$ & 73 & $1.77( \pm 1.16)$ & 135 & $2.38( \pm 2.00)$ & 166 & $2.15( \pm 1.50)$ & 51 & $2.16( \pm 2.02)$ & 417 & $1.61( \pm 1.08)$ & 108 & $1.64( \pm 1.07)$ & 0.000 \\
\hline HDL (m & 73 & $1.49( \pm 0.40)$ & 136 & $1.53( \pm 0.40)$ & 168 & 1.68 & 51 & $1.42( \pm 0$. & 417 & $1.47( \pm$ & 108 & $( \pm 0.47)$ & 0.08 \\
\hline LDL (n & 73 & $3.22( \pm 0.93)$ & 136 & $3.54( \pm 1.11)$ & 167 & $3.44( \pm 1.01)$ & 53 & $3.84( \pm 0$ & 416 & $3.21( \pm$ & 108 & $2.86( \pm 0.97)$ & 0.000 \\
\hline $\operatorname{ALT}($ & 40 & $21.4( \pm 13.6)$ & 75 & $24.7( \pm 20.9)$ & 114 & $22.0( \pm 11.3)$ & 46 & $23.5( \pm 13.0)$ & 256 & $12.2(=$ & 68 & 20.5( & 0.000 \\
\hline AST (U/L) & 40 & $24.8( \pm 9.41)$ & 76 & $29.6( \pm 13.9)$ & 111 & $28.5( \pm 8.92)$ & 45 & $29.0( \pm 10.0)$ & 254 & $25.8( \pm 9.45)$ & 68 & $32.3( \pm 10.6)$ & 0.000 \\
\hline ALP (U/L) & 30 & $60.9( \pm 45.9)$ & 52 & $62.2( \pm 24.4)$ & 75 & $74.8( \pm 23.0)$ & 33 & $73.0( \pm 20.6)$ & 193 & $71.9( \pm 31.5)$ & 13 & $78.3( \pm 22.2)$ & 0.083 \\
\hline $\mathrm{TB}(\mu \mathrm{mol} / \mathrm{L})$ & 40 & $10.2( \pm 5.9)$ & 76 & $11.0( \pm 4.4)$ & 114 & $10.8( \pm 4.9)$ & 46 & $10.6( \pm 4.3)$ & 258 & $11.1( \pm 4.2)$ & 69 & $9.4( \pm 4.6)$ & 0.222 \\
\hline $\operatorname{Cre}(\mu \mathrm{mol} / \mathrm{L})$ & 40 & $59.6( \pm 14.0)$ & 76 & $69.2( \pm 19.5)$ & 115 & $72.6( \pm 19.4)$ & 47 & $77.7( \pm 19.2)$ & 258 & $83.3( \pm 26.1)$ & 69 & $90.0( \pm 26.3)$ & 0.000 \\
\hline $\mathrm{UA}(\mu \mathrm{mol} / \mathrm{L})$ & 33 & $304( \pm 83)$ & 65 & $322( \pm 93)$ & 95 & $347( \pm 92)$ & 44 & $362( \pm 90)$ & 197 & $362( \pm 94)$ & 69 & $330( \pm 86)$ & 0.000 \\
\hline BMI $\left(\mathrm{kg} / \mathrm{m}^{2}\right)$ & 30 & $23.8( \pm 3.9)$ & 53 & $23.9( \pm 3.6)$ & 76 & $23.0( \pm 3.4)$ & 35 & $22.2( \pm 3.5)$ & 187 & $19.2( \pm 3.6)$ & 12 & $19.7( \pm 3.5)$ & 0.000 \\
\hline $\operatorname{BMR}\left(\mathrm{kJm}^{-2} \mathrm{~h}^{-1}\right)$ & 29 & $1160( \pm 138)$ & 53 & $1168( \pm 242)$ & 76 & $1112( \pm 191)$ & 35 & $1099( \pm 223)$ & 187 & $835( \pm 182)$ & 12 & $864( \pm 146)$ & 0.000 \\
\hline $\mathrm{BFR}(\%)$ & 30 & $29.9( \pm 8.9)$ & 52 & $28.0( \pm 9.6)$ & 76 & $27.8( \pm 8.4)$ & 35 & $26.1( \pm 7.1)$ & 187 & $24.8( \pm 9.4)$ & 12 & $22.4( \pm 10.6)$ & 0.006 \\
\hline PBW (\%) & 29 & $51.4( \pm 5.9)$ & 53 & $52.5( \pm 5.5)$ & 76 & $51.8( \pm 4.8)$ & 35 & $51.7( \pm 6.3)$ & 187 & $48.1( \pm 2.9)$ & 12 & $54.2( \pm 10.4)$ & 0.000 \\
\hline $\operatorname{VFI}\left(\mathrm{kg} / \mathrm{m}^{2}\right)$ & 29 & $5.28( \pm 3.00)$ & 52 & $7.07( \pm 3.54)$ & 76 & $7.30( \pm 3.40)$ & 34 & $8.39( \pm 4.37)$ & 187 & $8.53( \pm 3.81)$ & 12 & $6.96( \pm 2.64)$ & 0.000 \\
\hline BOM $(\mathrm{kg})$ & 30 & $2.26( \pm 0.31)$ & 53 & $2.32( \pm 0.37)$ & 76 & $2.11( \pm 0.38)$ & 35 & $2.11( \pm 0.51)$ & 187 & $1.45( \pm 0.49)$ & 12 & $1.56( \pm 0.44)$ & 0.000 \\
\hline
\end{tabular}

Abbreviations: Glu, blood glucose; SBP, systolic blood pressure; DBP, diastolic blood pressure; TC, total cholesterol; TG, triglyceride; HDL, high-density lipoprotein; LDL, low-density lipoprotein; ALT, alanine transaminase; AST, aspartate transaminase; ALP, alkaline phosphatase; TB, total bilirubin; Cre, creatinine; UA, uric acid; BMI, body mass index; BMR, basic metabolism rate; $\mathrm{BFR}$, body fat rate; $\mathrm{PBW}$, percent body water; $\mathrm{VFI}$, visceral fat index; $\mathrm{BOM}$, bone mass.
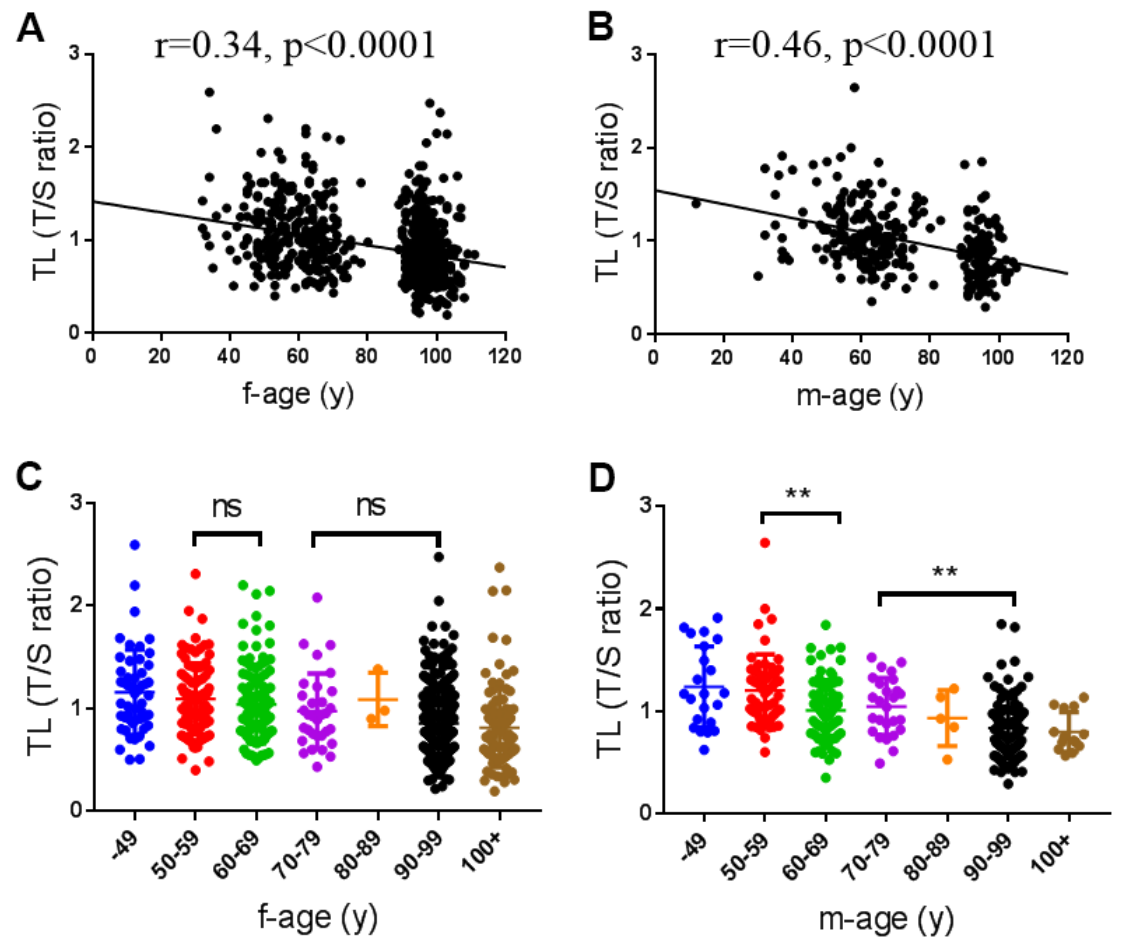

Figure 1. Associations of telomere length (TL) with age. (A, B) Scatter plot of TL with age in female ( $n=720)$ and male subjects ( $n=289)$, respectively. (C, D) The distribution of TL in female and male at different age groups. $f$, female; $m$, male. 
Table 2. Age-adjusted intrafamilial correlations of telomere length (TL).

\begin{tabular}{lccc}
\hline Relationship & No. of pairs & $\boldsymbol{r}$ & $\boldsymbol{p}$-value \\
\hline Mother-children & 76 & 0.44 & 0.0001 \\
Mother-daughter & 19 & 0.62 & 0.01 \\
Mother-son & 57 & 0.35 & 0.01 \\
Father-children & 32 & 0.23 & 0.36 \\
Father-daughter & 10 & 0.41 & 0.36 \\
Father-son & 22 & 0.19 & 0.46 \\
\hline
\end{tabular}

\section{Telomere length is related to lipid metabolism}

In order to identify potential factors that may affect TL, we tested the correlations between TL and various clinical indicators in Table 1. As shown in Table 3, most clinical variables, such as blood glucose (Glu), blood pressure, or blood lipids were not statistically associated with TL, except for percent body water (PBW, \% $)(\mathrm{r}=0.15, \mathrm{p}=0.004)$ and visceral fat index (VFI) $\quad(\mathrm{r}=-0.18, \quad \mathrm{p}<0.0001) . \quad$ Interestingly, the correlations existed only in females but not in males (Table 3). In addition, we found that AST, an index that clinically reflects the liver function, was weakly but significantly correlated with TL in females $(r=-0.10$, $\mathrm{p}=0.043$, Table 3). Among the TL-associated factors, VFI has the strongest correlation with TL (Table 3 and Figure 2A). Furthermore, we found that genes related to lipid metabolism were highly co-expressed with those related to TL maintenance (Supplementary Table 2). As liver is the major organ for lipid metabolism, we infer that TL is likely to be affected by lipid metabolism. To test this, we randomly selected 144 samples to measure their serum proteins by proteomics. After adjustment for age, the most relevant proteins with TL were apolipoproteins A (ApoA), including ApoA2 ( $\mathrm{r}=0.27$, $\mathrm{p}=0.001$, Figure 2B) and ApoA1 $(\mathrm{r}=0.19, \mathrm{p}=0.02$, Figure $2 \mathrm{C}$ ). As ApoA are critically involved in lipid metabolism in the liver [30], we tested the TL after interfering the key genes (PNPLA2 and CPT1) in a liver-derived cell line HepG2 (Figure $3 \mathrm{~A}$ ), and found that knockdown of either genes sufficiently caused lipid accumulation (Figure 3B), and shortened the TL (Figure 3B, 3C). These findings suggest that impairment of lipid metabolism affects the TL in the liver.

\section{DISCUSSION}

Although the general characteristics and influencing factors of TL have been reported in multiple Caucasian populations, data are still lacking in Chinese population. In this study, we analyzed the relationship of TL with age, gender, and the potential influencing factors, as well as the inheritance pattern of TL across generations in a Chinese population for the first time. We found that TL decreased along with age, but was better maintained in females than males. Moreover, we showed that TL was maternally inherited, with a robust relation between mother and their offspring. We further revealed that TL is related to lipid metabolism, such as visceral fat accumulation, liver function and serum ApoA protein levels. Thus, telomere maintenance is likely determined by genetic factors and shaped by non-genetic influences throughout human life.

Some studies have found that females have longer TL than males [12, 31, 32], which is likely associated with the protective role of oestrogen in stimulating telomerase to add telomere repeats to the ends of chromosomes [12]. In addition, telomeres are very sensitive to oxidative stress [33], and women produce fewer reactive oxygen species (ROS) than men [12]. However, it is not always the case that TL is longer in women than men $[34,35]$ or even the reverse [36]. In our study, although there were not any differences in TL between men and women in the same age group, we found that TL was better maintained in females than males with the age increase. TL was dynamically attritted with age and affected by a variety of environmental factors, such as occupational exposures [37], household income [35], and lifestyle (dietary patterns, drinking, smoking, and physical activity) [38-40]. Generally, males have higher risk to occupational exposures, higher rate of drinking and smoking, accounting for their accelerated telomere attrition in relative to females.

The inheritance pattern of telomere has been reported in several studies. A cross-sectional study and metaanalysis involving 19,713 European subjects aged 15-99 years showed that maternal inheritance of TL is stronger than paternal inheritance [41]. Based on the wholegenome sequencing of the Dutch population, Nersisyan et al. showed that TL tends to be inherited maternally [42]. A previous study based on a population of northern Belgium reported that the inheritance of $\mathrm{TL}$ was linked to the $\mathrm{X}$ chromosome [12]. However, several studies showed that TL was inherited from the paternal line or no parental bias $[13,14,43]$. These discrepancies may be attributed to differences in the genetic background or health status of the recruited subjects. Our results support that TL is maternally inherited in 
Table 3. Correlations between telomere length and indicators involved.

\begin{tabular}{|c|c|c|c|c|c|c|}
\hline & $\mathbf{r}(\mathbf{a l l})$ & $p$-value & $\mathbf{r}(\mathbf{f})$ & $P$-value & $\mathbf{r}(\mathbf{m})$ & $p$-value \\
\hline height $(\mathrm{kg})$ & 0.02 & 0.71 & 0.04 & 0.51 & -0.02 & 0.885 \\
\hline $\operatorname{BMI}\left(\mathrm{kg} / \mathrm{m}^{2}\right)$ & -0.08 & 0.096 & -0.07 & 0.222 & -0.12 & 0.280 \\
\hline $\mathrm{BM} \mathrm{kJ} /(\mathrm{m} 2 \cdot \mathrm{h})$ & -0.06 & 0.23 & -0.08 & 0.188 & -0.01 & 0.902 \\
\hline $\operatorname{BFR}(\%)$ & -0.09 & 0.09 & -0.07 & 0.241 & -0.16 & 0.137 \\
\hline PBW(\%) & 0.15 & 0.004 & 0.14 & 0.018 & 0.17 & 0.110 \\
\hline VFI $\left(\mathrm{kg} / \mathrm{m}^{2}\right)$ & -0.18 & 0.000 & -0.21 & 0.000 & -0.10 & 0.350 \\
\hline $\mathrm{BOM}(\mathrm{kg})$ & -0.02 & 0.63 & -0.04 & 0.530 & 0.06 & 0.613 \\
\hline weight(kg) & -0.08 & 0.14 & -0.08 & 0.184 & -0.05 & 0.658 \\
\hline $\mathrm{Glu}(\mathrm{mmol} / \mathrm{L})$ & 0.01 & 0.77 & -0.01 & 0.789 & 0.13 & 0.119 \\
\hline SBP(mmhg) & -0.02 & 0.66 & -0.03 & 0.474 & 0.03 & 0.699 \\
\hline DBP(mmhg) & -0.03 & 0.45 & -0.03 & 0.437 & -0.01 & 0.922 \\
\hline $\mathrm{TC}(\mathrm{mmol} / \mathrm{l})$ & 0.03 & 0.33 & 0.04 & 0.294 & -0.01 & 0.932 \\
\hline $\mathrm{TG}(\mathrm{mmol} / \mathrm{L})$ & 0.001 & 0.99 & -0.02 & 0.658 & 0.03 & 0.591 \\
\hline $\mathrm{HDL}(\mathrm{mmol} / \mathrm{L})$ & -0.04 & 0.22 & -0.03 & 0.455 & -0.12 & 0.051 \\
\hline $\mathrm{LDL}(\mathrm{mmol} / \mathrm{L})$ & 0.05 & 0.16 & 0.07 & 0.06 & -0.04 & 0.558 \\
\hline $\mathrm{ALT}(\mathrm{U} / \mathrm{L})$ & -0.05 & 0.27 & -0.07 & 0.118 & 0.03 & 0.753 \\
\hline $\operatorname{AST}(\mathbf{U} / \mathbf{L})$ & -0.08 & 0.07 & -0.10 & 0.043 & -0.02 & 0.770 \\
\hline ALP(U/L) & 0.04 & 0.411 & 0.06 & 0.287 & -0.04 & 0.694 \\
\hline $\mathrm{TB}(\mu \mathrm{mol} / \mathrm{L})$ & 0.07 & 0.098 & 0.07 & 0.123 & 0.05 & 0.575 \\
\hline $\operatorname{Cre}(\mu \mathrm{mol} / \mathrm{L})$ & -0.03 & 0.47 & -0.03 & 0.597 & -0.06 & 0.476 \\
\hline $\mathrm{UA}(\mu \mathrm{mol} / \mathrm{L})$ & -0.03 & 0.56 & -0.04 & 0.46 & -0.003 & 0.972 \\
\hline
\end{tabular}

Parameters and values in bold represent statistically significant correlation.

Abbreviations: all, all samples; f, female; $\mathrm{m}$, male; $\mathrm{BMI}$, body mass index; BMR, basic metabolism rate; BFR, body fat rate; PBW, percent body water; VFI, visceral fat index; BOM, bone mass; Glu, blood glucose; SBP, systolic blood pressure; DBP, diastolic blood pressure; TC, total cholesterol; TG, triglyceride; HDL, high-density lipoprotein; LDL, low-density lipoprotein; ALT, alanine transaminase; AST, aspartate transaminase; ALP, alkaline phosphatase; TB, total bilirubin; Cre, creatinine; UA, uric acid.

the Chinese population, which is the first study to test the inheritance pattern of TL in Chinese. We found a significant inheritance correlation between mother and their offspring, either in mother-daughter or mother-son comparisons. Interestingly, the mother-daughter TL correlation was higher than mother-son TL correlation. The mechanisms have yet to be investigated, but the beneficial effect of oestrogen on telomere maintenance [12] and lower occupational exposures in females [44], as well as the XX sex chromosome effect [45] may act in the differential correlation. In contrast, we did not observe any correlations for TL between father and their offspring. Due to the Chinese traditional culture, parents usually live with their sons when their children grow up and get married. Though the sample number of fatherdaughter pairs was too small to test the heritability between father and daughter, neither the correlation was there between father-son TL even the sample number was acceptable. Totally, our study suggests that TL is inheritable in Chinese population from the maternally line.

Many other influencing factors for TL have been reported, including cardiovascular diseases, diabetes and obesity, etc. [40, 46-48]. Here we found that TL is negatively correlated with visceral fat, and positively correlated with some ApoA levels even after age adjustment. Some studies have reported an inverse relationship between body mass index (BMI) and TL $[16,18]$, which was not observed in our study. Obesity defined by BMI is remarkably heterogeneous. People with similar body weight or BMI values can have substantially different comorbidities and levels of health risk [49]. Instead, visceral fat mass may be the real culprit that links telomeres with various metabolic diseases. Data from several epidemiological studies have shown that visceral adipose tissue is an independent risk factor of morbidity and mortality [49]. 
Emerging evidence also suggest that visceral fat deposition contributes to increased atherosclerosis and cardiometabolic risk [50]. Moreover, obesity is a key factor in the development of metabolic abnormalities [51], including metabolic syndrome, systemic chronic inflammation and oxidative stress. Apolipoproteins were closely related to lipid metabolism and affect body fat distribution [52]. The ApoA-TL correlation lends additional support to that TL is likely to be affected by lipid metabolism. Additionally, we found that AST, an indicator of liver function, was inversely related with TL. Consistent with previous studies [16], we found the correlation between TL and lipid metabolism existed only in females, which is possibly associated with sex hormone or other yet unknown $\mathrm{X}$ chromosomeharboring genes. There is an oestrogen-responsive element in human telomerase reverse transcriptase (hTERT) [53], so the hormone may stimulate telomerase and further maintain TL in females. In addition, the $\mathrm{X}$ chromosome harbors some genes, such as the DKC1 and AGTR2, which are important for maintaining the telomerase activity $[54,55]$. TL is likely to affect female health by mutually interacting with lipid metabolism. As telomere attrition is implicated in cellular senescence, TL maintenance may facilitate the homeostasis of lipid metabolism via regulating cellular senescence in adipose tissue [56]. On the other hand, excess adipose tissue can induce chronic and systemic inflammatory state [57], which can cause TL shortening by inducing ROS production and resultant oxidative stress [24]. However, the casual relationship between TL and lipid metabolism has yet to be investigated. Our preliminary data revealed that knockdown of the key genes for lipid metabolism caused fat accumulation and significantly shortened the $\mathrm{TL}$ in the liver cells, lending additional support to the observations in the population study. Nevertheless, more mechanistic studies are needed to explain the genderspecific differences and influencing factors for TL in the future.

Above all, our findings indicate that TL is maternally inherited, and impairment of lipid metabolism may contribute to the TL shortening in the Chinese population.
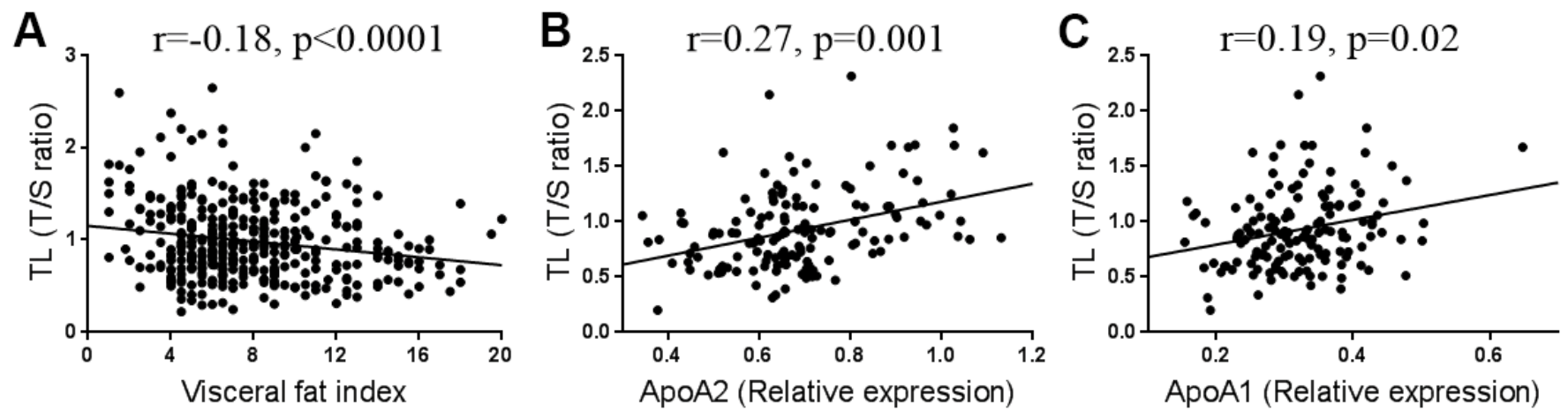

Figure 2. Correlation between telomere length (TL) and visceral fat $(n=394)(A), \operatorname{ApoA2}(n=144)(B)$, and ApoA1 levels ( $n=144)(C)$.
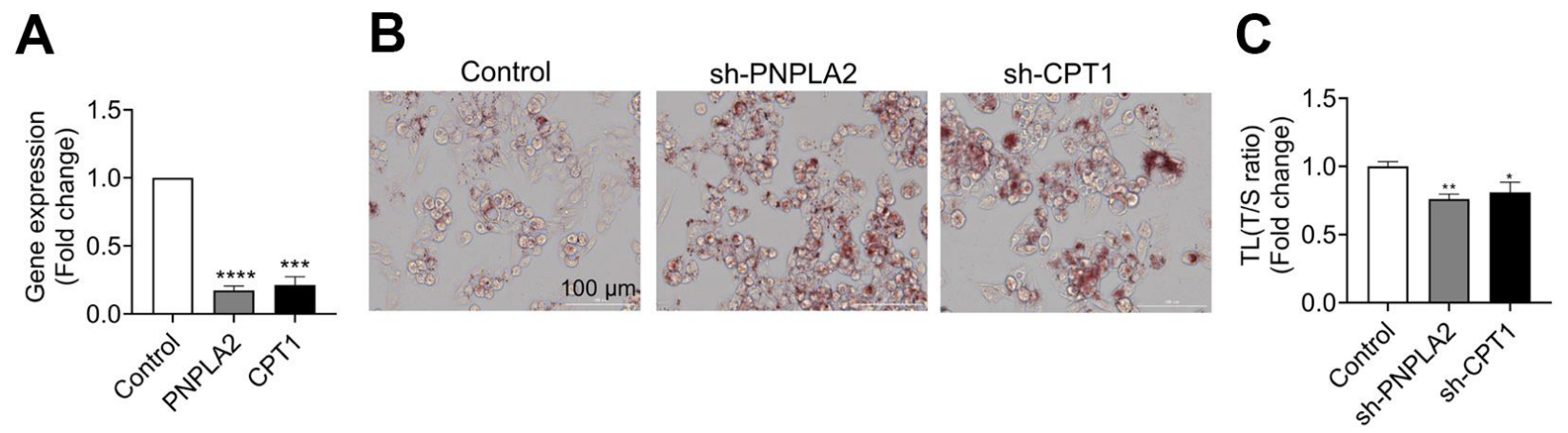

Figure 3. Knockdown of genes for lipid metabolism shortened telomere length (TL) in HepG2 cells. PNPLA2 and CPT1 genes were knocked down by short-hairpin RNA (shRNA) in HepG2 cells. (A) Efficiency of gene knockdown by short-hairpin RNA (shRNA) was evaluated by qPCR. (B) Oil red $O$ staining in HepG2 cells after PNPLA2 and CPT1 knockdown by shRNA. (C) TL was determined by qPCR in HepG2 cells. Data were expression as mean \pm SEM. ${ }^{*} p<0.05,{ }^{* *} p<0.01,{ }^{* * *} p<0.001,{ }^{*} * * * p<0.0001$. 


\section{MATERIALS AND METHODS}

\section{Study population}

In this study, 1031 participants aged from 12 to 111 years from Hainan Province (785 subjects) and Hubei Province (246 subjects) of China were recruited. The participants included 547 healthy elderly individuals, 188 offspring of the old (F1), 236 spouses of F1 (F1SP). The familial information was not available for the rest 60 individuals, who were not included into the inheritance analysis. A total of 108 families were used to assess the association of TL between the parents and their F1 offspring. Identity card was used to verify the participants' age and written informed consent was obtained from each of the participants. The study protocol was approved by the Ethics Committee at Kunming Institute of Zoology, Chinese Academy of Sciences.

\section{Telomere length measurement}

We collected blood samples from all participants and stored them in a $-30^{\circ} \mathrm{C}$ refrigerator. Genomic DNA was extracted from blood samples by AxyPrep Blood Genomic DNA Miniprep Kit (Corning, NY, USA) and stored at $-80^{\circ} \mathrm{C}$. We measured the average TL by quantitative PCR (qPCR) as described by Cawthon et al. [58]. Briefly, the standard curves of TL and single gene ( $\beta$-globin gene, HGB) amplification response were obtained from a reference DNA sample that continuously diluted with double distilled water by 4-fold per dilution to obtain 4 concentrations of DNA ranging from 0.94 to $60 \mathrm{ng} / \mu \mathrm{L}$. Reference DNA comprised mixed DNA from 60 individuals who were randomly selected from the 1031 subjects in this study. Each PCR reactions were carried out using about 20 ng DNA in a $20 \mu \mathrm{L}$ volume by FastStart Essential DNA Green Master (Roche, Basle, Switzerland). The primer sequences are TELF, 5'-CGGTTTGTTTGGGTTTGGGTTTGG GTTTGGGTTTGGGTT-3'; TELR, 5'-G GCTTGCC TTACCCTTACCCTTACCCTTACCCTTACCCT-3'; HGBF, 5'-GCTT CTGACACAACTGTGTTCACT AGC-3'; and HGBR, 5'-CACCAACTTCATCCAC GTTCACC -3 '. Cycling conditions were $95^{\circ} \mathrm{C}$ for $10 \mathrm{~min}$ followed by 30 cycles of $95^{\circ} \mathrm{C}$ for $10 \mathrm{sec}$ and $56^{\circ} \mathrm{C}$ for $30 \mathrm{sec}$ for TEL, $95^{\circ} \mathrm{C}$ for $10 \mathrm{~min}$ followed by 35 cycles of $95^{\circ} \mathrm{C}$ for $10 \mathrm{sec}$ and $58^{\circ} \mathrm{C}$ for $20 \mathrm{sec}$ for HGB. TL was expressed as T/S where $\mathrm{T}$ indicates telomere repeats $(\mathrm{T})$ and $\mathrm{S}$ indicates the copy number of single copy genes $(\mathrm{S})$. T/S values were calculated by the formula $2^{-\Delta \Delta \mathrm{Ct}}$, where $\Delta \Delta \mathrm{Ct}=\mathrm{C}_{\mathrm{t}}$ (samples) ${ }^{\text {telomere }}-\mathrm{C}_{\mathrm{t} \text { (samples) }}$-globin $^{\beta}-\mathrm{C}_{\mathrm{t} \text { (reference) }}$ telomere $-\mathrm{C}_{\mathrm{t}}$ (reference) $\beta$-globin

\section{Biochemical measurements of peripheral blood}

Blood biochemical indicators were tested in clinical laboratories of local hospitals. $2 \mathrm{~mL}$ peripheral blood sample for each subject was sent to hospital within three hours after collecting. The indicators included blood glucose (Glu), total cholesterol (TC), triglyceride (TG), high-density lipoprotein (HDL), low-density lipoprotein (LDL), alanine transaminase (ALT), aspartate transaminase (AST), alkaline phosphatase (ALP), total bilirubin (TB), creatinine (Cre), and uric acid (UA).

\section{Measurements of body composition}

Body composition was measured by a body fat scale (InBody, Cheonan city, South Korea). The working principle of the scale was described previously [59]. Briefly, subjects were required to stretch out their arms to avoid contact with waist, put their thumbs on the round electrodes, place their heels at the end of the heel electrodes. Body compositions included body mass index (BMI), basic metabolism rate (BMR), body fat rate (BFR), percent body water $(\mathrm{PBW})$, visceral fat index (VFI), and bone mass (BOM).

\section{Measurements of serum proteins}

Relative proteins were quantified using Tandem Mass Tag mass spectrometry by PTM BIOLABS company. Firstly, the top 12 high abundance proteins were removed from serum samples by Pierce Top 12 Abundant Protein Depletion Spin Columns Kit (Thermo Fisher Scientific, Waltham, MA, USA). Trypsin was then used for the protein digestion. After trypsin digestion, peptide was desalted by Strata $\mathrm{X}$ C18 SPE column (Phenomenex, CA, USA) and labelled according to the manufacturer's protocol for TMT kit/iTRAQ kit (Thermo Fisher Scientific, Waltham, MA, USA). Then, the tryptic peptides were fractionated into fractions by high $\mathrm{pH}$ reverse-phase HPLC using Thermo Betasil C18 column. The peptides were subjected to NSI source followed by tandem mass spectrometry (MS/MS) in Q ExactiveTM Plus (Thermo Fisher Scientific, Waltham, MA, USA) coupled online to the UPLC. Finally, the resulting MS/MS data were processed using Maxquant search engine (v.1.5.2.8). Tandem mass spectra were searched against the Uniprot database concatenated with reverse decoy database.

\section{Cell culture, short-hairpin RNA (shRNA), Oil Red O staining and measurement of TL}

HepG2 and HEK-293T cells were cultured in Dulbecco's modified Eagle medium (Sigma-Aldrich, St. Louis, MO, USA) supplemented with $10 \%$ heat- 
inactivated fetal bovine serum (Thermo Fisher Scientific, Waltham, MA, USA), and $1 \%$ penicillin/streptomycin (Thermo Fisher Scientific, Waltham, MA, USA) in a humidified incubator at $37^{\circ}$ $\mathrm{C}$ and $5 \% \mathrm{CO}_{2}$. shRNAs targeting PNPLA2 and CPT1 were cloned into EGFP-pLKO.1 lentiviral vector. The lentiviruses were harvested from HEK-293T cells, and then transfected into HepG2 cells. Infected cells were selected for 3 passages in medium containing $2 \mu \mathrm{g} / \mathrm{mL}$ puromycin. The efficiency of shRNA knockdown was evaluated by qPCR. Sequences used for shRNA and primers for qPCR were listed in Supplementary Table 3. After knockdown of the target genes, lipid was stained with Oil Red O (Sigma-Aldrich, St. Louis, MO, USA) and cell photos were taken using Nikon inverted microscope. TL was measured using qPCR after PNPLA2 and CPT1 knockdown in HepG2 cells according to the method as described [60].

\section{Data analysis}

Most of the statistical analyses were performed with SPSS 21.0 (SPSS Inc., Chicago, IL, USA). Continuous variables were expressed as mean $\pm \mathrm{SD}$ and compared by the One-Way ANOVA or nonparametric test according to the distribution of data. Multiple linear regression was used to evaluate the contribution of multiple indicators to TL. The correlation coefficient between TL and indicators involved was assessed by Pearson correlation coefficient or partial correlation analysis (adjusted age and gender). Significance of the difference between the age-TL correlation coefficients in females and males were tested using an online tool (http://vassarstats.net/rdiff.html). The expression data for genes involved in lipid metabolism and TL maintenance were extracted from the RNA-seq data (not shown) in our lab, and the associations between two gene sets were measured by Pearson correlation analysis in R platform. Data of gene knockdown and TL in cell experiments were expressed as mean \pm SEM and analyzed using the GraphPad Prism 7 software (GraphPad Software, La Jolla, CA, USA). All comparisons were made by two-tailed. $P$ values less than 0.05 were considered statistically significant.

\section{Abbreviations}

ALP: alkaline phosphatase; ALT: alanine transaminase; AST: aspartate transaminase; BFR: body fat rate; BMI: body mass index; BMR: basic metabolism rate; $\mathrm{BOM}$ : bone mass; Cre: creatinine; DBP: diastolic blood pressure; Glu: blood glucose; HDL: high-density lipoprotein; PBW: percent body water; LDL: lowdensity lipoprotein; SBP: systolic blood pressure; TB: total bilirubin; TC: total cholesterol; TG: triglyceride; UA: uric acid; VFI: visceral fat index.

\section{AUTHOR CONTRIBUTIONS}

YH initiated and supervised the study. $\mathrm{YH}$ and $\mathrm{LG}$ wrote the manuscript. LG, YC, HL, LH and MZ conducted experiments and researched the data. LG, FY and MG performed statistical analyses. ZQ critically reviewed and edited the manuscript.

\section{CONFLICTS OF INTEREST}

The authors declare that they have no conflicts of interest.

\section{FUNDING}

This work was supported by grants from the National Natural Science Foundation of China (82171558, 82071595), the Strategic Priority Research Program (XDPB17) and Key Research Program (KFZD-SW221) of the Chinese Academy of Sciences. Additional support was received from Yunnan Applied Basic Research Project (2017FA038, 2019FB094), and the National Key R\&D Program of China (No. 2018YFC2000400, 2018YFE0203700).

\section{REFERENCES}

1. Blackburn EH. Structure and function of telomeres. Nature. 1991; 350:569-73. https://doi.org/10.1038/350569a0 PMID:1708110

2. Lu W, Zhang $Y$, Liu $D$, Songyang $Z$, Wan $M$. Telomeresstructure, function, and regulation. Exp Cell Res. 2013; 319:133-41.

https://doi.org/10.1016/i.yexcr.2012.09.005 PMID:23006819

3. Levy MZ, Allsopp RC, Futcher AB, Greider CW, Harley $\mathrm{CB}$. Telomere end-replication problem and cell aging. J Mol Biol. 1992; 225:951-60. https://doi.org/10.1016/0022-2836(92)90096-3 PMID:1613801

4. Soler D, Genescà A, Arnedo G, Egozcue J, Tusell L. Telomere dysfunction drives chromosomal instability in human mammary epithelial cells. Genes Chromosomes Cancer. 2005; 44:339-50. https://doi.org/10.1002/gcc.20244 PMID: 16052508

5. Turner KJ, Vasu V, Griffin DK. Telomere Biology and Human Phenotype. Cells. 2019; 8:73. https://doi.org/10.3390/cells8010073 PMID:30669451

6. Demanelis $K$, Jasmine $F$, Chen LS, Chernoff $M$, Tong L, Delgado D, Zhang C, Shinkle J, Sabarinathan M, Lin H, Ramirez E, Oliva M, Kim-Hellmuth S, et al, and GTEx Consortium. Determinants of telomere length across human tissues. Science. 2020; 369:eaaz6876. 
https://doi.org/10.1126/science.aaz6876

PMID:32913074

7. Kajstura J, Pertoldi B, Leri A, Beltrami CA, Deptala A, Darzynkiewicz Z, Anversa P. Telomere shortening is an in vivo marker of myocyte replication and aging. Am J Pathol. 2000; 156:813-9.

https://doi.org/10.1016/S0002-9440(10)64949-8 PMID:10702397

8. Blasco MA. Telomeres and human disease: ageing, cancer and beyond. Nat Rev Genet. 2005; 6:611-22. https://doi.org/10.1038/nrg1656 PMID:16136653

9. Blackburn EH, Epel ES, Lin J. Human telomere biology: A contributory and interactive factor in aging, disease risks, and protection. Science. 2015; 350:1193-8.

https://doi.org/10.1126/science.aab3389 PMID:26785477

10. Graakjaer J, Pascoe L, Der-Sarkissian H, Thomas G, Kolvraa S, Christensen K, Londoño-Vallejo JA. The relative lengths of individual telomeres are defined in the zygote and strictly maintained during life. Aging Cell. 2004; 3:97-102.

https://doi.org/10.1111/i.1474-9728.2004.00093.x

PMID:15153177

11. Vasa-Nicotera $M$, Brouilette $S$, Mangino $M$, Thompson $J R$, Braund P, Clemitson JR, Mason A, Bodycote CL, Raleigh SM, Louis E, Samani NJ. Mapping of a major locus that determines telomere length in humans. Am J Hum Genet. 2005; 76:147-51.

https://doi.org/10.1086/426734

PMID:15520935

12. Nawrot TS, Staessen JA, Gardner JP, Aviv A. Telomere length and possible link to $\mathrm{X}$ chromosome. Lancet. 2004; 363: 507-10.

https://doi.org/10.1016/S0140-6736(04)15535-9

PMID:14975611

13. Nordfjäll K, Larefalk A, Lindgren $P$, Holmberg D, Roos G. Telomere length and heredity: Indications of paternal inheritance. Proc Natl Acad Sci USA. 2005; 102:16374-8.

https://doi.org/10.1073/pnas.0501724102

PMID:16258070

14. Njajou OT, Cawthon RM, Damcott CM, Wu SH, Ott S, Garant MJ, Blackburn EH, Mitchell BD, Shuldiner AR, Hsueh WC. Telomere length is paternally inherited and is associated with parental lifespan. Proc Natl Acad Sci USA. 2007; 104:12135-9.

https://doi.org/10.1073/pnas.0702703104

PMID:17623782

15. Eisenberg DT. Inconsistent inheritance of telomere length $(T L)$ : is offspring $T L$ more strongly correlated with maternal or paternal TL? Eur J Hum Genet. 2014; 22:8-9. https://doi.org/10.1038/ejhg.2013.202

PMID:24022299

16. Nordfjäll K, Eliasson M, Stegmayr B, Melander O, Nilsson P, Roos G. Telomere length is associated with obesity parameters but with a gender difference. Obesity (Silver Spring). 2008; 16:2682-9.

https://doi.org/10.1038/oby.2008.413 PMID:18820651

17. Al-Attas OS, Al-Daghri N, Bamakhramah A, Shaun Sabico S, McTernan P, Huang TT. Telomere length in relation to insulin resistance, inflammation and obesity among Arab youth. Acta Paediatr. 2010; 99:896-9. https://doi.org/10.1111/j.1651-2227.2010.01720.x PMID:20178511

18. Müezzinler A, Zaineddin AK, Brenner H. Body mass index and leukocyte telomere length in adults: a systematic review and meta-analysis. Obes Rev. 2014; 15:192-201.

https://doi.org/10.1111/obr.12126 PMID:24165286

19. Benetos A, Okuda K, Lajemi M, Kimura M, Thomas F, Skurnick J, Labat C, Bean K, Aviv A. Telomere length as an indicator of biological aging: the gender effect and relation with pulse pressure and pulse wave velocity. Hypertension. 2001; 37:381-5.

https://doi.org/10.1161/01.hyp.37.2.381

PMID:11230304

20. Arsenis NC, You T, Ogawa EF, Tinsley GM, Zuo L. Physical activity and telomere length: Impact of aging and potential mechanisms of action. Oncotarget. 2017; 8:45008-19.

https://doi.org/10.18632/oncotarget.16726

PMID:28410238

21. Semeraro MD, Smith C, Kaiser M, Levinger I, Duque G, Gruber HJ, Herrmann M. Physical activity, a modulator of aging through effects on telomere biology. Aging (Albany NY). 2020; 12:13803-23.

https://doi.org/10.18632/aging.103504

PMID:32575077

22. Epel ES, Blackburn EH, Lin J, Dhabhar FS, Adler NE, Morrow JD, Cawthon RM. Accelerated telomere shortening in response to life stress. Proc Natl Acad Sci USA. 2004; 101:17312-5.

https://doi.org/10.1073/pnas.0407162101 PMID:15574496

23. Astuti $Y$, Wardhana $A$, Watkins J, Wulaningsih $W$, and PILAR Research Network. Cigarette smoking and telomere length: A systematic review of 84 studies and meta-analysis. Environ Res. 2017; 158:480-9.

https://doi.org/10.1016/i.envres.2017.06.038 PMID:28704792

24. Barnes RP, Fouquerel E, Opresko PL. The impact of oxidative DNA damage and stress on telomere homeostasis. Mech Ageing Dev. 2019; 177:37-45. 
https://doi.org/10.1016/i.mad.2018.03.013 PMID:29604323

25. Zhang J, Rane G, Dai X, Shanmugam MK, Arfuso F, Samy RP, Lai MK, Kappei D, Kumar AP, Sethi G. Ageing and the telomere connection: An intimate relationship with inflammation. Ageing Res Rev. 2016; 25:55-69.

https://doi.org/10.1016/i.arr.2015.11.006 PMID:26616852

26. He YH, Pu SY, Xiao FH, Chen XQ, Yan DJ, Liu YW, Lin R, Liao XP, Yu $Q$, Yang LQ, Yang XL, Ge MX, Li Y, et al. Improved lipids, diastolic pressure and kidney function are potential contributors to familial longevity: a study on 60 Chinese centenarian families. Sci Rep. 2016; 6:21962. https://doi.org/10.1038/srep21962 PMID:26911903

27. He YH, Zhang YX, Yang LQ, Liao XP, Zhang QY, Cai WW, Kong QP. Assessment of the health status of centenarians in the south of China: a cross-sectional study. J Am Geriatr Soc. 2014; 62:1402-4.

https://doi.org/10.1111/igs.12895 PMID:25039520

28. He YH, Chen XQ, Yan DJ, Xiao FH, Liu YW, Lin R, Liao XP, Cai WW, Kong QP. Thyroid Function Decreases with Age and May Contribute to Longevity in Chinese Centenarians' Families. J Am Geriatr Soc. 2015; 63:1474-6.

https://doi.org/10.1111/igs.13553 PMID:26189854

29. Atzmon G, Barzilai N, Hollowell JG, Surks MI, Gabriely I. Extreme longevity is associated with increased serum thyrotropin. J Clin Endocrinol Metab. 2009; 94:1251-4. https://doi.org/10.1210/ic.2008-2325 PMID:19158193

30. Dixon JL, Ginsberg HN. Hepatic synthesis of lipoproteins and apolipoproteins. Semin Liver Dis. 1992; 12:364-72.

https://doi.org/10.1055/s-2008-1040406 PMID:1465621

31. Bekaert $S$, De Meyer T, Rietzschel ER, De Buyzere ML, De Bacquer D, Langlois $M$, Segers $P$, Cooman L, Van Damme $\mathrm{P}$, Cassiman $\mathrm{P}$, Van Criekinge $\mathrm{W}$, Verdonck $\mathrm{P}$, De Backer GG, et al, and Asklepios investigators. Telomere length and cardiovascular risk factors in a middle-aged population free of overt cardiovascular disease. Aging Cell. 2007; 6:639-47. https://doi.org/10.1111/j.1474-9726.2007.00321.x PMID: 17874998

32. Fitzpatrick AL, Kronmal RA, Gardner JP, Psaty BM, Jenny NS, Tracy RP, Walston J, Kimura M, Aviv A. Leukocyte telomere length and cardiovascular disease in the cardiovascular health study. Am J Epidemiol. 2007; 165:14-21. https://doi.org/10.1093/aje/kwj346 PMID:17043079
33. von Zglinicki T. Oxidative stress shortens telomeres. Trends Biochem Sci. 2002; 27:339-44. https://doi.org/10.1016/s0968-0004(02)02110-2 PMID:12114022

34. Hunt SC, Chen W, Gardner JP, Kimura M, Srinivasan SR, Eckfeldt JH, Berenson GS, Aviv A. Leukocyte telomeres are longer in African Americans than in whites: the National Heart, Lung, and Blood Institute Family Heart Study and the Bogalusa Heart Study. Aging Cell. 2008; 7:451-8. https://doi.org/10.1111/i.1474-9726.2008.00397.x PMID:18462274

35. Shiels PG, McGlynn LM, Maclntyre A, Johnson PC, Batty GD, Burns H, Cavanagh J, Deans KA, Ford I, McConnachie A, McGinty A, McLean JS, Millar K, et al. Accelerated telomere attrition is associated with relative household income, diet and inflammation in the pSoBid cohort. PLoS One. 2011; 6:e22521. https://doi.org/10.1371/journal.pone.0022521 PMID:21818333

36. Adams J, Martin-Ruiz C, Pearce MS, White M, Parker L, von Zglinicki T. No association between socioeconomic status and white blood cell telomere length. Aging Cell. 2007; 6:125-8. https://doi.org/10.1111/i.1474-9726.2006.00258.x PMID:17156082

37. Kahl VF, da Silva J. Inorganic elements in occupational settings: A review on the effects on telomere length and biology. Mutat Res Genet Toxicol Environ Mutagen. 2021; 872:503418.

https://doi.org/10.1016/i.mrgentox.2021.503418 PMID: 34798938

38. Davinelli S, Trichopoulou A, Corbi G, De Vivo I, Scapagnini G. The potential nutrigeroprotective role of Mediterranean diet and its functional components on telomere length dynamics. Ageing Res Rev. 2019; 49:1-10.

https://doi.org/10.1016/i.arr.2018.11.001 PMID:30448616

39. Gardner M, Bann D, Wiley L, Cooper R, Hardy R, Nitsch D, Martin-Ruiz C, Shiels $P$, Sayer AA, Barbieri $M$, Bekaert S, Bischoff C, Brooks-Wilson A, et al, and Halcyon study team. Gender and telomere length: systematic review and meta-analysis. Exp Gerontol. 2014; 51:15-27. https://doi.org/10.1016/j.exger.2013.12.004 PMID:24365661

40. Valdes AM, Andrew T, Gardner JP, Kimura M, Oelsner E, Cherkas LF, Aviv A, Spector TD. Obesity, cigarette smoking, and telomere length in women. Lancet. 2005; 366:662-4. https://doi.org/10.1016/S0140-6736(05)66630-5 PMID:16112303 
41. Broer L, Codd V, Nyholt DR, Deelen J, Mangino M, Willemsen G, Albrecht $E$, Amin N, Beekman $M$, de Geus EJ, Henders A, Nelson CP, Steves CJ, et al. Meta-analysis of telomere length in 19,713 subjects reveals high heritability, stronger maternal inheritance and a paternal age effect. Eur J Hum Genet. 2013; 21:1163-8.

https://doi.org/10.1038/ejhg.2012.303

PMID:23321625

42. Nersisyan L, Nikoghosyan M, Arakelyan A, and Genome of the Netherlands consortium. WGS-based telomere length analysis in Dutch family trios implicates stronger maternal inheritance and a role for RRM1 gene. Sci Rep. 2019; 9:18758.

https://doi.org/10.1038/s41598-019-55109-7

PMID:31822713

43. Nordfjäll K, Svenson U, Norrback KF, Adolfsson R, Roos G. Large-scale parent-child comparison confirms a strong paternal influence on telomere length. Eur J Hum Genet EJHG. 2010; 18:385-9.

https://doi.org/10.1038/ejhg.2009.178

PMID:19826452

44. Eng A, 't Mannetje A, McLean D, Ellison-Loschmann L, Cheng $S$, Pearce N. Gender differences in occupational exposure patterns. Occup Environ Med. 2011; 68:888-94.

https://doi.org/10.1136/oem.2010.064097

PMID:21486991

45. Davis EJ, Lobach I, Dubal DB. Female XX sex chromosomes increase survival and extend lifespan in aging mice. Aging Cell. 2019; 18:e12871.

https://doi.org/10.1111/acel.12871

PMID:30560587

46. Epel ES, Merkin SS, Cawthon R, Blackburn EH, Adler NE, Pletcher MJ, Seeman TE. The rate of leukocyte telomere shortening predicts mortality from cardiovascular disease in elderly men. Aging (Albany NY). 2008; 1:81-8.

https://doi.org/10.18632/aging.100007

PMID:20195384

47. Haycock PC, Heydon EE, Kaptoge S, Butterworth AS, Thompson A, Willeit P. Leucocyte telomere length and risk of cardiovascular disease: systematic review and meta-analysis. BMJ. 2014; 349:g4227.

https://doi.org/10.1136/bmj.g4227

PMID:25006006

48. Shen Q, Zhao X, Yu L, Zhang Z, Zhou D, Kan M, Zhang D, Cao L, Xing Q, Yang Y, Xu H, He L, Liu Y. Association of leukocyte telomere length with type 2 diabetes in mainland Chinese populations. J Clin Endocrinol Metab. 2012; 97:1371-4.

https://doi.org/10.1210/ic.2011-1562

PMID:22319045
49. Hiuge-Shimizu A, Kishida K, Funahashi T, Ishizaka $Y$, Oka R, Okada M, Suzuki S, Takaya N, Nakagawa T, Fukui T, Fukuda H, Watanabe N, Yoshizumi T, et al. Absolute value of visceral fat area measured on computed tomography scans and obesity-related cardiovascular risk factors in large-scale Japanese general population (the VACATION-J study). Ann Med. 2012; 44:82-92.

https://doi.org/10.3109/07853890.2010.526138 PMID:20964583

50. Tchernof A, Després JP. Pathophysiology of human visceral obesity: an update. Physiol Rev. 2013; 93:359-404.

https://doi.org/10.1152/physrev.00033.2011

PMID:23303913

51. Saltiel AR, Olefsky JM. Inflammatory mechanisms linking obesity and metabolic disease. J Clin Invest. 2017; 127:1-4. https://doi.org/10.1172/JCI92035 PMID:28045402

52. Sadeghi M, Pourmoghaddas Z, Hekmatnia A, Sanei $H$, Tavakoli B, Tchernof A, Roohafza H, Sarrafzadegan N. Association of apolipoprotein B, apolipoprotein A, and the its ratio with body fat distribution. J Res Med Sci. 2013; 18:326-9.

PMID:24124431

53. Kyo S, Takakura M, Kanaya T, Zhuo W, Fujimoto K, Nishio $\mathrm{Y}$, Orimo A, Inoue $\mathrm{M}$. Estrogen activates telomerase. Cancer Res. 1999; 59:5917-21. PMID: 10606235

54. Mitchell JR, Wood E, Collins K. A telomerase component is defective in the human disease dyskeratosis congenita. Nature. 1999; 402:551-5. https://doi.org/10.1038/990141 PMID:10591218

55. Volpe M, Musumeci B, De Paolis P, Savoia C, Morganti A. Angiotensin II AT2 receptor subtype: an uprising frontier in cardiovascular disease? J Hypertens. 2003; 21:1429-43.

https://doi.org/10.1097/00004872-200308000-00001 PMID: 12872031

56. Liu Z, Wu KK, Jiang $X, X u A$, Cheng KK. The role of adipose tissue senescence in obesity- and ageingrelated metabolic disorders. Clin Sci (Lond). 2020; 134:315-30.

https://doi.org/10.1042/CS20190966

PMID:31998947

57. Ouchi N, Parker JL, Lugus JJ, Walsh K. Adipokines in inflammation and metabolic disease. Nat Rev Immunol. 2011; 11:85-97.

https://doi.org/10.1038/nri2921

PMID:21252989

58. Cawthon RM. Telomere measurement by quantitative PCR. Nucleic Acids Res. 2002; 30:e47. 
https://doi.org/10.1093/nar/30.10.e47

PMID:12000852

59. Peltz G, Aguirre MT, Sanderson M, Fadden MK. The role of fat mass index in determining obesity. Am J Hum Biol. 2010; 22:639-47.

https://doi.org/10.1002/ajhb.21056

PMID:20737611
60. Lee HW, Park TI, Jang SY, Park SY, Park WJ, Jung SJ, Lee $\mathrm{JH}$. Clinicopathological characteristics of TERT promoter mutation and telomere length in hepatocellular carcinoma. Medicine (Baltimore). 2017; 96:e5766.

https://doi.org/10.1097/MD.0000000000005766 PMID: 28151853 


\section{SUPPLEMENTARY MATERIALS}

\section{Supplementary Figure}
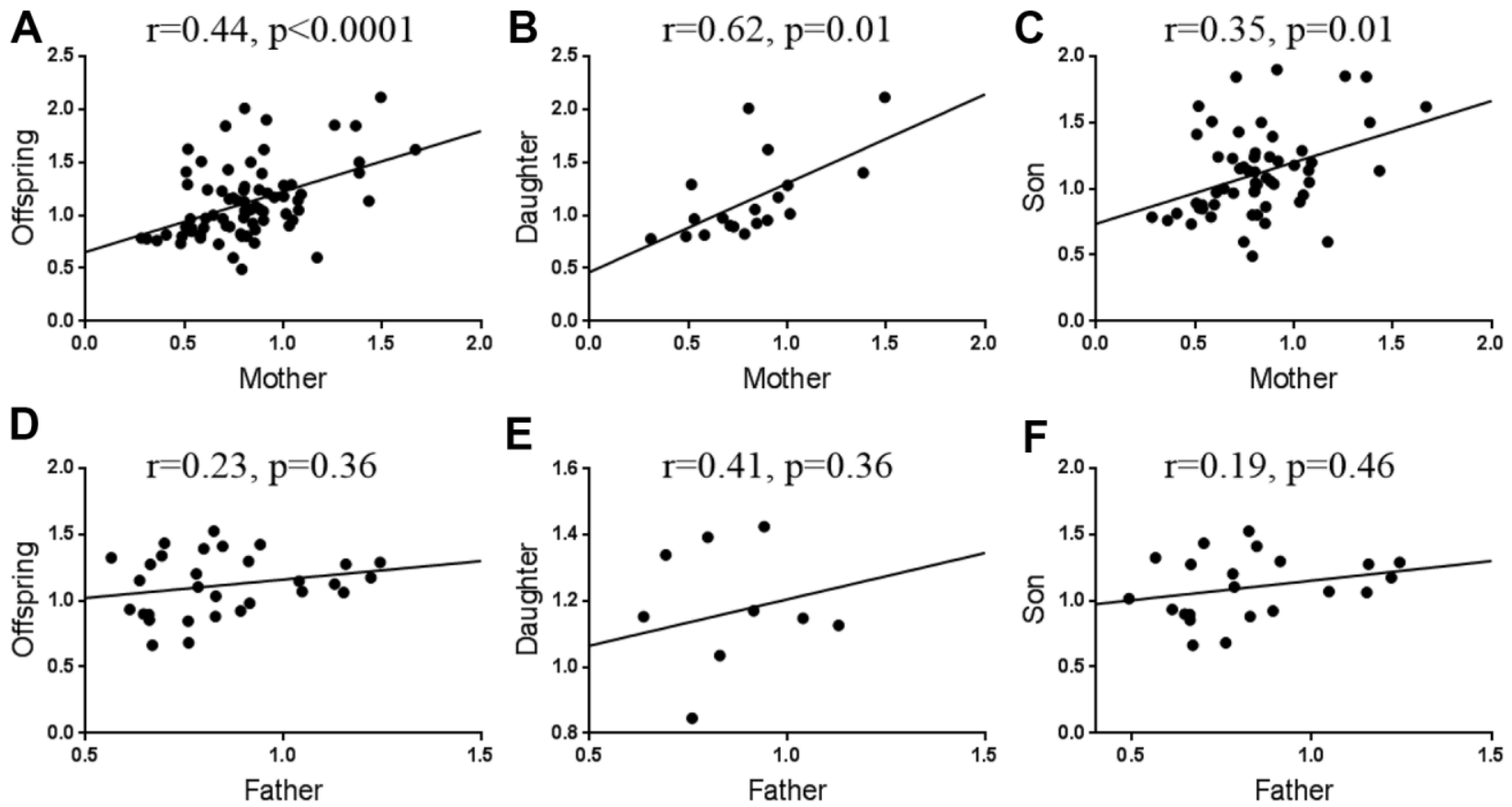

Supplementary Figure 1. Intrafamilial associations of telomere length. (A) mother vs. offspring. (B) mother vs. daughter. (C) mother vs. son. (D) father vs. offspring. (E) father vs. daughter. (F) father vs. son. 


\section{Supplementary Tables}

Please browse Full Text version to see the data of Supplementary Table 2.

Supplementary Table 1. Telomere length distribution by gender and age.

\begin{tabular}{|c|c|c|c|c|c|c|}
\hline \multirow{2}{*}{ Age (y) } & \multicolumn{2}{|c|}{ Tel-all } & \multicolumn{2}{|c|}{ Tel-female } & \multicolumn{2}{|c|}{ Tel-male } \\
\hline & $\mathbf{N}$ & $\operatorname{mean}( \pm \mathrm{SD})$ & $\mathbf{N}$ & $\operatorname{mean}( \pm \mathrm{SD})$ & $\mathbf{N}$ & $\operatorname{mean}( \pm \mathrm{SD})$ \\
\hline-49 & 74 & $1.19 \pm 0.40$ & 52 & $1.17 \pm 0.41$ & 22 & $1.24 \pm 0.39$ \\
\hline $50-59$ & 149 & $1.15 \pm 0.34$ & 95 & $1.11 \pm 0.33$ & 54 & $1.21 \pm 0.35$ \\
\hline 60-69 & 177 & $1.04 \pm 0.34$ & 105 & $1.05 \pm 0.38$ & 72 & $1.03 \pm 0.28$ \\
\hline 70-79 & 58 & $1.01 \pm 0.33$ & 32 & $0.98 \pm 0.37$ & 26 & $1.04 \pm 0.28$ \\
\hline $80-89$ & 8 & $0.99 \pm 0.26$ & 3 & $1.09 \pm 0.26$ & 5 & $0.93 \pm 0.27$ \\
\hline 90-99 & 428 & $0.85 \pm 0.31$ & 331 & $0.85 \pm 0.31$ & 97 & $0.83 \pm 0.29$ \\
\hline $100+$ & 115 & $0.81 \pm 0.37$ & 102 & $0.81 \pm 0.38$ & 13 & $0.76 \pm 0.18$ \\
\hline total & 1009 & $0.96 \pm 0.36$ & 720 & $0.94 \pm 0.37$ & 289 & $1.00 \pm 0.34$ \\
\hline
\end{tabular}

Note: Among the 1031 participants, 22 did not have either age or gender information so that they were not included for the analysis in the table.

Supplementary Table 2. Expression associations of the telomere length (TL) related genes with lipid metabolism related genes.

Supplementary Table 3. Sequences used for shRNA and primers for qPCR in the in-vitro study.

\begin{tabular}{lcc}
\hline & Forward & Reverse \\
\hline \multirow{2}{*}{ shPNPLA2 } & CCGGGCCAAGTTCATTGAGGTATCTCTCG & AATTCAAAAAGCCAAGTTCATTGAGGTATC \\
& AGAGATACCTCAATGAACTTGGC TTTTTG & TCTCGAGAGATACCTCAATGAACTTGGC \\
shCPT1 & CCGGCGATGTTACGACAGGTGGTTTCTCG & AATTCAAAAACGATGTTACGACAGGTGGTT \\
qPCR-PNPLA2 & AGAAACCACCTGTCGTAACATCG TTTTTG & TCTCGAGAAACCACCTGTCGTAACATCG \\
qPCR-CPT1 & GAGATGTGCAAGCAGGGATAC & CTGCGAGTAATCCTCCGCT \\
\hline
\end{tabular}

